\title{
Exploring the Reflective Learning Experiences of Primary School Teachers during the use of Open Educational Resources
}

\author{
S. O. Essuman \\ University of Education, Winneba, Ghana \\ Email: sessuman@uew.edu.gh, sallyessuman@gmail.com
}

Received: May 20, 2015 Accepted: May 28, 2015 Published: June 11, 2015

doi:10.5296/jet.v2i2.7793 URL: http://dx.doi.org/10.5296/jet.v2i2.7793

\begin{abstract}
This paper looks at the reflective learning experiences of primary school teachers, who were encouraged to engage in reflective activities as a way of improving their pedagogical practice during the use of Open Educational Resources (OER). The assumption of the study was that OERs have the potential to improve teachers' pedagogical content knowledge and skills, as well as their networking and collaborative activities and impact on their professional practice. Ten (10) out of forty-two (42) primary school teachers, who participated in a training workshop focused on the use of OER, were purposively sampled to keep a reflective journal of their learning experiences and share the outcomes with their colleagues. Interviews were used in collecting data from the cohort. Using phenomenology as a methodology and content analysis as a tool for analyzing the data collected, the 'stories' of these teachers were analyzed manually and presented in a report at a seminar. The findings indicated that teachers acknowledged the added values that OER have had on their pedagogical practice; the influence that the new knowledge and skills have had on students' learning and the enthusiasm that students exhibited when active learning strategies were used in teaching. However, the reflective learning elements that teachers were expected to exhibit in their writing were lacking. The deep thinking and learning from their critical analysis of their experiences were not evident in their responses. It is recommended that sessions on reflective teaching, learning and writing should be incorporated into pre- and in-service teachers' training sessions. Skill building in reflective writing and learning should be introduced to teachers early in practice and during training for them to build the culture of reflection in teaching.
\end{abstract}

Keywords: reflective learning, open educational resources, professional practice, pedagogical concepts 


\section{Introduction}

Presently, many institutions offering teacher education programmes have incorporated reflective learning components into their initial preparation courses as a pre-requisite to their qualification. This is to enable teachers become reflective practitioners by the time they complete their programmes. The purpose is to help develop a link between theory and practice so that the training of teachers becomes informed by more practically grounded learning experiences. At the University of Education, Winneba, teacher preparation has emphasized the 'teacher' as a reflective decision-maker who ought to facilitate student learning in their practice. In this regard, opportunities are provided for newly qualified teachers to enhance their ability to engage in reflective practice whilst at the University. This includes keeping reflective journals, building teaching portfolios and conducting action research. All these activities are carried out during their school-based internship, commonly known as teaching practicum, which is a six-credit course. However, the question is: what rigorous practical experiences do these teachers go through to enable them write real reflective learning papers? What requisite skills in reflective writing do they possess and also do they know how to continue to reflect on their teaching experiences, to improve upon their practice? Further, as in-service training activities are rolled out for teachers how do they collaborate, network and learn in their professional practice? This study seeks to explore the skills of these schoolteachers in reflective learning and keeping reflective journals after acquiring new knowledge in OER use.

It is worth mentioning that the University is a member of a consortium that developed some OER and set out to introduce the resource to some primary school teachers in its catchment area for the purpose of improving their classroom practices. Specifically, the OER were the kind developed by the 'Teacher Education in Sub-Saharan Africa' (TESSA). TESSA is a consortium, made up of thirteen African Universities and in collaboration with the Open University of UK. The purpose of TESSA is to support teacher professional development in the sub-region. In this regard, some in-service teachers were nominated for training in the use of the OER after which the respondents in this study were encouraged to keep a reflective journal as a way of recording their learning experiences in teaching. However, the issues remain to be explored whether the training had influenced their professional practice or not and in what ways. Further, it was thought that if this strategy had a chance to improve teachers' practice, then it would be necessary to consider the manner in which the findings could be used to assist many more teachers.

Reflection in its generic term is understood to be 'those intellectual and effective activities in which individuals engage in to explore their experiences in order to lead them into new understanding and appreciation' (Kolb, 1984). Writers including Schőn, Dewey, and Boud in the literature agree to the fact that the concept of reflection implies an active and conscious process that is continuous in one's life. In other words, reflection is a positive active process that reviews, analyses and evaluates experiences, drawing on theoretical concepts of previous learning experiences so as to provide an action plan for future experiences. 
The overall goal of this study is to explore teachers' learning experiences from their reflections during the use of the TESSA OER in their classroom practice. Secondly, it is to emphasize reflective learning and writing of teachers in their professional practice. The underpinning theoretical framework for the study is the experiential learning cycle by Kolb and Gibbs.

\subsection{Research Questions}

Specifically, the study was guided by the following questions:

1) What is the perceived value of using TESSA OER by primary school teachers in their classroom practice?

2) How are basic school teachers learning from reflection as they use TESSA OER?

3) In what ways have teachers collaborated and networked with others during the use of TESSA OER?

4) What challenges do teachers encounter as they keep and write in their reflective journals?

\section{Literature Review}

\subsection{What is Reflective Learning?}

Reflective learning, as defined by Boyd and Fales (1983), is the process of internally examining and exploring an issue of concern, triggered by an experience, which creates and clarifies meaning in terms of self, and which results in a changed conceptual perspective. In addition, they suggest that this process is central to understanding the experiential learning process of any reflection activity. Moon (1999), on the other hand, defines reflection as a form of mental processing with a purpose and/or anticipated outcome that is applied to relatively complex or unstructured ideas for which there is not an obvious solution and it largely refers to the further processing of knowledge and understanding that we already possess $(1999$, p.23). What is implied in these definitions is that the process of reflection and learning should serve a purpose and have an anticipated outcome. At the same time reflection should benefit the individual reflecting by he or she learning from the outcome through self-development engagements. Moon (1999) further states that in an academic context, reflective learning or reflection is likely to involve a conscious and stated purpose for the reflection, with an outcome that is specified in terms of learning action or clarification. In other words, academic reflection may be seen as the process of an outcome that could be preceded by a description of an incident or a subject matter, analyzed and assessed. In this regard, there would be factors that could affect the nature and quality of the process.

Mezirow's transformation theory, which is one of the many definitions of learning, describes learning as a process of critical self-reflection or self-evaluation. He states that learning is the process of using a prior experience to understand a new or revised interpretation of that experience in order to guide future action (Mezirow, 1991). Again, in the literature, Kolb (1984), Boud et al. (1993) and Dietz (1998) have all identified learning, and for that matter reflective learning as a cyclic model. Kolb's experiential learning cycle, which is used as one 
of the frameworks to understand a teacher's learning experience is a four-stage cycle beginning with the concrete experience followed by reflection then by abstract conceptualization and active experimentation as shown in Figure 1.

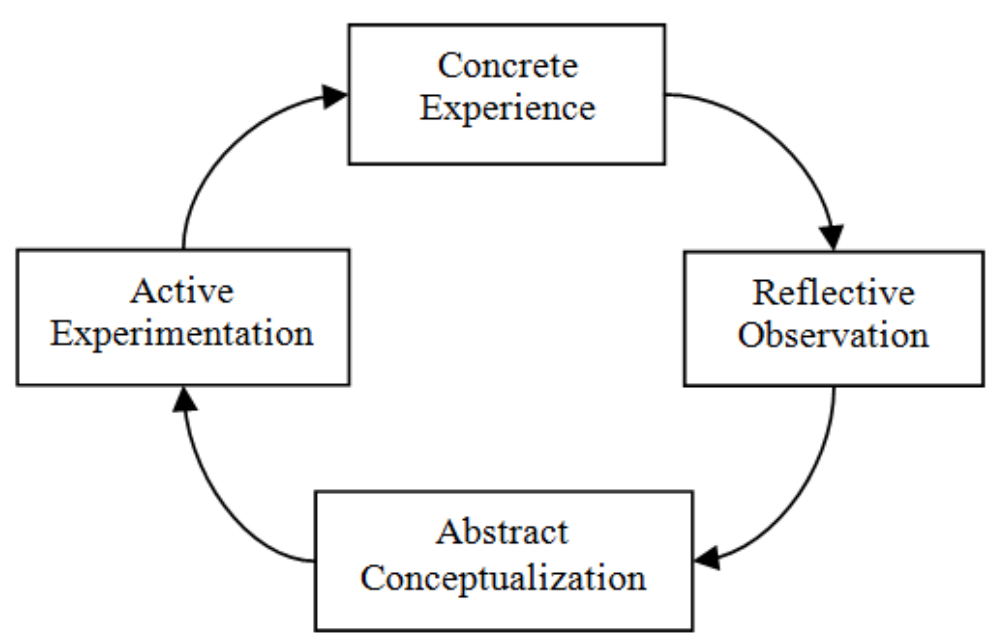

Figure 1. Kolb's (1984) cycle of experiential learning

This model of experiential learning process depicts how an individual's experience is translated into new concepts through reflection and leading the individual back to the first stage and so on. The understanding gathered from this model is that the results of experiences lead learners to new knowledge or solution or method which becomes another concrete experience that the learner reflects on and conceptualizes findings and modifies or applies the new concepts in other similar situations. In this vein, a teacher's delivery after a lesson may be considered as the concrete experience; then pondering over how the delivery occurred and what he/she learnt from it would emerge the strengths and areas for improvement. It could be argued that a teacher's pedagogical concepts, which are conceptual and methodological tools that he/she uses to design a lesson plan on a topic, implements this lesson and assesses its outcome may be analyzed in this context with a learning notion in focus. Pedagogy is understood to be the art as well as the science of teaching; a master-plan that includes a detailed analysis of what is to be done by a teacher (Bhowmik et al., 2013). Therefore, for a teacher to achieve the learning outcomes of a lesson, different strategies may be used in different combinations with different groups of students to meet the needs of everyone in the class. Incorporating an array of teaching strategies that support intellectual engagement, connectedness to the wider world, supportive classroom environments and recognition of differences may be termed as the pedagogical conceptualization of the teacher.

Boud et al. (1993) on another hand, proposes a three-stage model of learning, which includes the preparation for the experience, the experience itself and then the reflection on the 
experience. Boud et al. (1993) explain reflection as a conscious activity in which we engage to explore our experiences and develop new understandings and conceptualizations (Boud, et al., 1989). In their view, learning during reflection from an experience should be a valued act especially with formal education. Dewey (1933), Kolb (1984), Dietz (1998) and others have all argued that emphasis should be placed on the learner's ability to actively construct knowledge during any reflection. Dietz (1998) describes the professional learning cycle as the 'translation of learning theory into cycles of professional development', which provides the means to make the connections between theory and practice real. These models identify reflection as a significant part of the learning cycle. As teachers happened to be familiar with routine classroom management tasks, adapting OER in ways that will modify their teaching plans and lessons should be welcome news. It is assumed that adopting/adapting a new pedagogical practice such as the use of OER to promote students' learning and improve teacher's confidence is of critical importance in the teaching profession.

Again, Gibbs (1998) reflective learning cycle, which appears to be an expansion of Kolbs experiential learning cycle also consists of six stages as shown in Figure 2 and stresses the need for analysis of feelings and analysis to make sense of the experience so as to arrive at a new action plan in future. The cycle consists of:

1) Description of the event/situation

2) Analysis of feelings

3) Evaluation of the experience

4) Analysis to make sense of the experience

5) Conclusion with other considerations and

6) Action plan for a similar situation

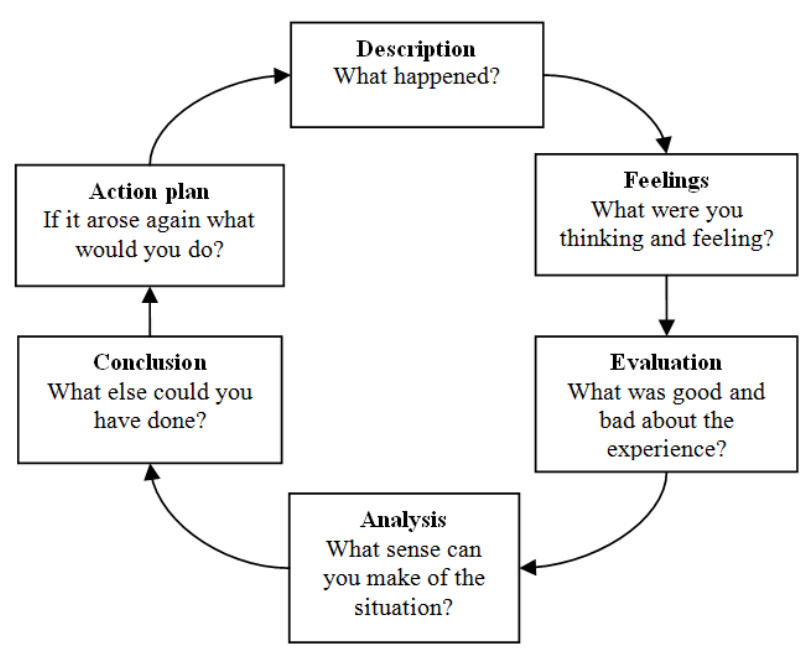

Figure 2. Gibbs (1998) reflective cycle 
In Gibbs reflective learning cycle (Figure 2), it is evident that Kolb's 'Reflective Observation' and 'Abstract Conceptualization' have been extended. In the Gibbs model (Park \& Son, 2011). In the Gibbs model, the former seems to have been extended to include Feelings and Evaluation and the latter in Analysis and Conclusion (ibid). Thus, in reviewing and superimposing teachers' reflective learning experiences from their classroom practice, this model serves as a framework to understand their 'stories'. Such 'stories' are likely to be documented in a diary or a journal and the latter is termed as a reflective journal or diary. In other words, reflective learning results into reflective writing, which results into reflective journals.

\subsection{What is a Reflective journal?}

A reflective journal is a means of recording ideas, personal thoughts and experiences, as well as reflections and insights a teacher/student has in the learning process of an event (Chan, 2009). Reflective journals could be in a form of unstructured or structured writing. The structured is where specific questions or set of guidelines are given for the writing to be based on. The unstructured is where the individual freely records his/her thoughts and feelings with minimal direction. Writing reflectively in a journal requires that the learner thinks deeply, to challenge his/her old ideas with new incoming information to synthesize them into new personal thoughts and philosophies and integrate them into their daily experiences as well as future actions (Moon, 1999). Several advantages seem to be associated with keeping a reflective journal and writing reflectively. For instance, it enhances one's critical thinking and creativity as well as providing the platform to freely critique one-self. In this vein, it can be assumed that reflective teachers would have the opportunity to invent and test new approaches to teaching such as using these TESSA OER in their practice. This exercise would call for lots of reflection and reflective learning through reformed pedagogical display of new knowledge and skills.

However, it needs to be mentioned that writing reflectively and keeping a reflective journal can be daunting. Reflective writing is a skill that needs to be developed and that needs constant practice and perseverance. Moon (1999) suggests that the use of a structured framework to enable learners reflect on appropriate issues could help them 'move on' in their thinking (1999). She proposes a seven-step framework for reflective writing for learners. These are:

1) Purpose (identify the purpose of the reflective activity)

2) Description (describe the events, context, personal behaviour and feelings)

3) Links (make links with ideas relating to the event, from experience or reading)

4) Revisiting (revisit the event and interpret it from a different point of view)

5) Stand Back (a little later make notes on the events testing the resulting ideas in other situations or discussing them with other people)

6) Results (identity has been learned or solved, or an area for further reflection that has been identified)

7) More Reflection (identify further possibilities for reflection). (Moon, 1999) 
For the teachers in this study, keeping a reflective journal could be seen as pivotal to their learning; in that, the TESSA OER are designed with lots of active learning strategies and teachers have to think creatively and undertake lots of pedagogical analysis to effectively implement them. By asking teachers to keep a reflective journal in this study, it is assumed that their continual reflections on their practice would be improved. They would build their self-confidence and improve their pupils' learning outcomes. Clark (2004) states that as a teacher, keeping a reflective journal is to provide you with an opportunity for a more focused look at your teaching strategies or the recurring problems of learners. Thus, these teachers were to keep reflective journals to record their daily and weekly events, their reactions, lesson planning, classroom management, pupils' learning and their own professional development.

\subsection{TESSA Open Educational Resources (TESSA OER)}

In the Literature, several definitions have been given to the term, Open Educational Resources (OER). This is because it is a movement that is linked to open learning. D'Antoni (2009) quotes UNESCO's definition of OER as the provision of educational resources, enabled by information and communication technologies, for consultation, use and adaptation by a community of users for non-commercial purposes. In the same D'Antoni (2009), William and Flora Hewlett Foundation, one of the primary champions in the OER movement defines it as:

... teaching, learning and research resources that resides in the public domain under an intellectual property license that permits their free use or re-purposing by other. Open educational resources include full courses, course materials, modules, textbooks, streaming videos, tests, software, and any other tools, materials or techniques used to support access to knowledge. (William and Flora Hewlett Foundation, 2008)

It can be gathered from the above quotation that the main characteristic of OER is that they are generally cost-free. This means that the costs borne by users are reduced by involving software programmers, legal experts and repository managers in the whole OER production process. Further, an evaluation report by UNESCO in 2005 revealed that people use OER for various reasons.

People who are neither teachers nor students in formal programmes access OER primarily to enhance their personal knowledge. Students who access OER do so mostly to complement a course they are taking, to enhance personal knowledge, and to plan their course of study. Teachers who access OER do so mostly to plan or prepare a course, enhance their personal knowledge, or learn about topics related to their research. [UNESCO, 2005] 
What this report seems to imply is that all stakeholders in society and in education in particular, such as students, teachers, educators and any individual could have access to OER knowledge to inform themselves. It is in a similar context that TESSA, [which, as defined above, stands for 'Teacher Education in Sub-Saharan Africa'] a global consortium consisting of organizations including the BBC World Service Trust, Commonwealth of Learning, some Teacher Education Universities in Sub-Saharan Africa and the Open University of U.K., set out to develop OER for teachers in Africa. It is worth mentioning that the TESSA OER is unique in the sense that it is audience specific to teachers and the teacher educator has to be in control of the initiative. TESSA OER were created collaboratively by teacher educators from across Africa, and over 100 authors were involved (Wolfenden, 2008). This aspect of the TESSA OER makes it stand out as interoperable since partner institutions cannot be seen as consumers of imported educational material, as is commonly known but rather as collaborators in content, production, distribution and utilization (ibid). The TESSA OER resources have been developed to meet the needs of teachers specifically in the sub-region who have challenges with teaching resources. Underpinning the materials is a curriculum of key pedagogical strategies and skills for the teacher to develop and improve his/her practices. The model is focused on the school as the site for professional learning supported by local structures. Thus, teachers using TESSA OER are to be able to continue to attend to their own learners whilst studying, integrating teaching and studying within their context (Wolfenden, 2008). This is one reason why the teachers in this study after their training were encouraged to keep a reflective learning journal as they use the OER in their teaching experiences. Though, the OER movement seems to have a strong rhetoric about the potential for adaptation, the TESSA OER has the diversity of its created materials developed from and for a number of different environments and languages. It has a template for adoption, adaptation and creativity. Again, TESSA has a range of media, particularly, audio (broadcast radio), which is a resource that has both motivational as well as informative power for its users. With this teachers using TESSA OER have the opportunity to modify their teaching and learning environments.

\section{Methodology}

The research tradition that was considered suitable for this study is the qualitative approach using phenomenology method. This method rests on an assumption that there is a structure and essence to share an experience that can be narrated (Pratt, 1992). It seeks to describe the meaning of a concept or phenomenon that several individuals share (Marshall \& Rossman, 1999), as it is in the case of these teachers using the TESSA OER. Also, this method is useful for revealing how things appear from the viewpoint of the respondent as well as the researcher. With the researcher being familiar with the TESSA OER, the task was to discover and describe distinctively, different ways in which individuals related to the various elements in their contexts. Phenomenology is a method for describing qualitatively different ways in which people understand or conceptualize an aspect of their world. In this regard, the 'TESSA teachers' reflecting on the use of OERs and keeping a reflective journal will recount their experiences from the viewpoint of their contexts. 
A guiding framework for posing questions and interpreting the data was based on the learners: learning process, the content to be learned, the context (external factors that influenced teaching \& learning) and the teachers' own beliefs, actions and intentions during the use of the OER. It can be foreseen that these elements, serving as guidelines for interpreting the data would be interrelated and internally consistent. However, they would be defined and understood in ways that would be complementary and not contradictory. The findings of this study may not be generalized since a small number of teachers in their context have been used. It may be considered as an illuminative pilot study on teachers' reflective learning abilities.

Ten purposively sampled respondents were selected from a group of teachers who were introduced to the TESSA OER and trained to access, use and implement any of the strategies on their own in their classrooms. These teachers were selected from two circuits in the municipality where the University is located, namely: [the West, East and Central circuits]. Since the schools are widely scattered, the sample was based on convenience so that facilitators could visit them anytime in their schools to monitor their progress. As part of the monitoring exercise, brief interviews were conducted with their consent to find out how they were engaging with the OER. Among the variety of data collection methods in the literature, interview is considered as one kind that fosters face-to-face interactions with a respondent. It facilitates an immediate follow-up for clarification and the discovery of any nuances in culture. It also provides contextual information, facilitates cooperation and is useful for uncovering respondents' perspectives, though it could be prone to misinterpretations and ethical dilemmas. (Marshall and Rossman, 2006). Interviewees were assured of confidentiality and anonymity, as names of schools were not to be mentioned in the report. The interviews were tape-recorded, with their permission, for easy transcription. The interviews were conducted in English in a conversational manner rather than a series of questions though there was a brief semi-structured interview guide used by the researcher during the conversation. It needs to be mentioned that of the ten sampled at the start of the monitoring, only eight could be contacted during the visits. The other two did not honour their appointments as scheduled. Three visits each were made to the respondents during which the brief conversation took place.

\section{Analysis, Results and Discussions}

A systematic format for analyzing the data was designed having the research questions and purpose in mind. Data analysis started as soon as the first data were collected. The responses were transcribed verbatim and thoroughly read through several times so that the data would be familiar to me (the researcher). All the transcripts were numbered and during reading, memos were written at the margins of the transcripts to identify ideas and patterns emerging. When all data from interviewees had been obtained, the main key words and phrase were noted and used as codes for sorting and analyzing the data. It needs to be mentioned that the themes were deduced from the research questions and as phrases and words relating to the questions emerged, they were grouped into categories and then to themes. For example, under the theme 'perceived value of OER' sentences with words and phrases such as benefits of OER/usefulness of OER and many more were captured. So sentences with meanings close to 
such a theme were captured under that theme. Again, another theme was captured as: 'learning from reflection' and similarly, sentences with such meanings were placed under it. The same went for 'challenges' and 'collaboration/working with colleagues'. These categorizations were done manually by spreading the written themes on a tabletop and cutting up the transcriptions and putting them under the various themes. This strategy helped in organizing the data into categories and then condensed them under themes. Once the data were organized in this format it was easy to retrieve them. At the same time, any unanticipated new ideas were noted for discussion since they could give some other insight to the study. Findings from the analysis were set for discussion. Pseudonyms were used in identifying the different interviewees.

The results are excerpts from interviews conducted during the visits to find out about their reflective thinking. It needs to be mentioned that in reality what teachers kept in their reflective journals were recordings of what they taught and how they taught it and not deep thinking critical recordings of their feelings, beliefs, self-evaluations, and what was learnt from the experiences or what changes could be effected if another opportunity came up. Further enquiries about their journals revealed that they did not know how to write suitable reflective statements even though a sample format had been given to them at the training workshop. It was also assumed that as graduates from the University, where writing reflective papers were an aspect of their school-based internship activity, they would easily write it. But this exercise has proved that pre-service teachers' skills in reflective writing need to be emphasized.

\subsection{Perceived Value of Using TESSA OER}

Under this theme, I sought to explore the perceived value that teachers observed in their teaching during the use of the TESSA OER as posed in the research question one. All interviewees (8) indicated the great benefit that they had gained from the various strategies described in the OER, especially the key curriculum resources. They acknowledged the potential that the resources had in transforming their classroom environment. The following statements are samples from some of the teachers:

They [OER] are very interesting and it's been designed in such a way that they ensure full participation in class or lessons. It has helped me in my teaching, at first I was teaching most of the lessons in abstract to the pupils but since I started using the TESSA website I have been using real objects in my teaching. [Boakye]

I give them project work in groups and they do it together and come and present it in class. Pupils participate in class and even come out with new examples. [Gordon] 
It's been very interesting to the extent that with the TESSA model, it makes lessons more interesting and lively. So it is a place [the website] I visit often even on my phone and at rest. [Cindy]

... it's interesting now that the topic I'm teaching is 'Indiscipline'. I noticed that when a child misbehaves, they can easily rebuke the person and say that we watched the video show on indiscipline ... and it has brought me closer to them because when they have difficulties or problems, they come to me to seek for help or solutions [Ham].

The first one is interest, and this interest is lasting, right now if you go to my classroom and ask them how did we go about playing one game that we adopted from one TESSA resource ... It is popular with them, it keeps on and on; to stimulate and sometimes they will ask you, hello sir when will you do that activity we did last time again? I think it adds more knowledge to not only for the children but myself, the teacher, as well [Ruff].

Almost all interviewees (8) claimed the TESSA OER have made their lesson presentations easier, classrooms livelier and more interesting or exciting and helped pupils to retain contents learned. It has to be acknowledged that the strategies are mainly activity based with active learning strategies such as games, songs, role-play drama, small group work and others. As children, these strategies would definitely be interesting to them and help them to grasp concepts quickly. Most of these statements are expression of feelings and evaluation of what was good as Gibbs (1998) reflective cycle in Fig. 2 depicts. In this vein, these new learning experiences could have been compiled in their journals.

Again, as mentioned by some interviewees (4), the resources allow them to involve the children in lesson delivery, teach with real objects and not in abstract as they used to do. In terms of respondents' reflective learning experiences, these can be linked to Kolb's (1984) reflective observation and abstract conceptualization after the concrete experience. Their self-evaluations of how they felt about their new classroom environments seemed to be leading to action plans for improvement in their classroom practices. This finding supports Branch and Paranjape, (2007, in Monash, 2007) that 'reflection leads to growth of the individual- morally, personally, psychologically and emotionally as well as cognitively'. In other words, reflection is a necessary stage in identifying ones areas for improvement and professional growth as teachers. The statement by Ruff in the above quotations is an indication that he has grown, both personally and professionally, after reflection. Further, his values and beliefs have been challenged as he reflected. 


\subsection{Teachers Learning from their Reflections on the Use of TESSA OER}

When interviewees were asked how they were learning from their reflections, they had more to share in statements such as:

You see sometimes I can teach today and after reflecting I can see that, what I have done could have been done in a better way. So in my own view and my thinking is that, they are good, ... but we should get more Ghanaian episodes. So sometimes you have to rehearse many times before using it in class. You have to rehearse more or less like a mock in classroom situation, how you would do it. One day I was rehearsing and my wife was laughing at me ... Reflective writing is also another issues, that people don't know how to write, what at all are they reflecting on? I think one of the TESSA materials that I received had it... [Saleia]

Some of the activities in the TESSA might be quite lengthy, so I sometimes consider and select some of them considering my lesson period. And then personally in my own opinion, I just think that the games in the TESSA resources give different interest level in the classroom ... So this is what I normally do. It makes me improve on the one I have seen on TESSA. The model that people have used, I always try to improve on them. So this is what I normally do. One of the topics I have treated is the solar system and I used the idea in my class [Cindy].

Actually what I do is that, I go through the TESSA materials, read them and look at how it's been done elsewhere and then I follow the steps sometimes modify it and use it in preparing my lesson notes so I adopt and adapt them. For example, I use songs to arouse the interest of the pupils, to prepare their minds towards the lesson. I use songs, which are related to the topic to draw their attention to it. I adopted it from the TESSA resources. [Magda]

Under this theme most interviewees (6) responded positively indicating the learning experiences from their reflections on what they had accessed from the TESSA OER and the application in their lessons. Most of them seemed to indicate that their reflections were leading them to improve upon what they had been doing and giving them clues to making the learning environment lively. Some indicated that they have resolved to employ alternative ways such as using videos and audio recordings to present their lessons [Boakye]. Others seemed to rehearse after reflecting on an adopted strategy to be sure that he [Saleia] gets it correct before implementing it in class. All the quotations above have elements of learning from their experiences of using the TESSA OER. This links up well with the reflective learning cycles in the literature, where after description and analysis of a critical incident there is a review of learning and a new plan of action, which most of them resolved doing. 
As adult teachers, they had been learning from experiences and their learning is based on assumptions, which included: the need to know, readiness to learn and orientation to learning. Thus, their motivation to learn and their social contexts had all influenced them in their classroom practice. These practices could be seen to have conceptual underpinnings in Kolb and Gibbs learning cycles as discussed in the text. The two cycles indicate that learning is a process, which starts with the learner's experiences, which when reflected upon lead to new generations of actions in new situations. In other words, connections are made between theory and practice and teachers in this study seemed to be making such connections between what they have been doing and plan to do in future. They seemed to be moving from abstract teaching to planning lessons that take into consideration students' learning needs.

\subsection{Ways that Teachers have collaborated with others during the use of the TESSA OER?}

From interviewees' experiences, it is assumed that as they learned and relearned they will interact with their colleagues and share their new experiences with them. It emerged that some did even to a wide audience at the national level. This is what some of them had to say when they were asked to narrate how they had been spreading the 'TESSA news'.

I introduced the TESSA programme to my colleagues when I went to Ho (a town in the Volta Region of Ghana), for a national conference, that is, when I was attending the Ghana National Association of Teachers (GNAT) annual conference. I demonstrated it to the whole teachers' group and they were very happy. I also taught them how to access the TESSA website and other resources from the Internet. Now they are happy with it and so I'm more than a resource person in the group. [Johnny]

...With my colleague teachers, I do speak to them about TESSA and I've told them that if there is something they don't understand ... or anything, I will be willing to help them. Actually, most of them were not at the training so I've been showing them how to access the website and use the resources [Saleia]

For the District competition, I took a lesson from the TESSA resources and gave it to my mentee. He prepared the lesson for the District, I just supported him to come and observe it and it was wonderful. We won the prize for innovative teaching ... so sometimes you have to invite the teachers and refresh their minds. I'm lucky that in my school they see me to be more or less a master teacher in Mathematics. So they will come, sit behind in a demonstration lesson, observe, and then learn from each other. I also learn from them. [Ruff] 
It can be gathered from these quotations that teachers trained at the workshop were sharing the new knowledge with their colleague teachers. More than half (4) of the interviewees indicated that they had been networking and sharing the new found strategies and website with their colleagues in the profession. One interviewee indicated that he usually demonstrates how one can access information on any topic from the Internet and the website (www.tessafrica.net). He had the opportunity and demonstrated the use of it to other teachers at a national delegates conference of the 'Ghana National Association of Teachers (GNAT)'. As mentioned, he is now seen as a resource person for TESSA. Others are school-based and District-based trainers who from time to time meet their colleague teachers at gatherings for networking and exchange of ideas. With reflective learning experiences being a process, these teachers can easily explain how they have been learning from the use of these resources. The benefits derived from the learning experiences would add to their professional and personal growth.

Similarly, as one Mathematics teacher narrated that he is considered as a master teacher in Mathematics in the District and thus provides support services to other Mathematics teachers through demonstration lessons, this could be a fertile ground for him to be sharing his reflective learning experiences of TESSA use with the colleagues. Again, if he is carrying out a good reflective learning from his training session, there would be links between theory and practice for him to be able to improve upon his performance and future practice.

\subsection{Challenges Teachers Encounter as they Reflect and keep Reflective Journals}

In spite of the usefulness of using the TESSA OER there are these chronic problems, which are common challenges anytime the Internet is mentioned. For instance, some (3) interviewees indicated that:

Well sometimes it's difficult. Once I was trying to use the Internet during a lesson and immediately I started browsing the power just went off. The children were disappointed but there wasn't anything I could do. Again, another time too I was using the audio in class and as I was playing the lesson on environmental degradation; It got to a point that the kids were excited when suddenly the internet cut off because of power interruption ... [Johnny]

This is an issue prevalent in most activities carried out using the Internet or being dependent of the power system. Again, using the reflective learning cycle this teacher could describe the incidents, how he felt and evaluate the good or bad experience and then what he deeply learnt from those experiences.

I think the language of some of the materials and the activities ... because it is from other country's activity and that they had adopted were local ones and I was trying to get it more in tune with my pupils but its difficult. [Cindy] 
In the view of a few interviewees (2), there were songs and games that were localized or contextualized which made it difficult for them to adopt and adapt to them though they realized those resources could be helpful. They were of the opinion that if resources were being shared then a generic language should have been used. For example, some games were interesting watching but because of the language barrier they could not be of help to them. They could not be translated into the Ghanaian language. This made a teacher to comment that he seems not to have seen any Ghanaian play at the TESSA website:

On the TESSA OER, there are no Ghanaian plays and our scenarios are not much on the TESSA website; it should be evident that we also have something unique that we do in Ghana, which other countries can copy and adapt in their country. Again, when you go to the internet sometimes you wonder whether the TESSA resource are updated at all either monthly or annually or it is just a fixed thing that we have in our homes with no updating [Ruff]

The above comment raises an issue that is worth considering. The question is: when resources are developed do they undergo continuous updating or is it that once they are uploaded they are not updated again? On the other hand, it could be argued that the resources are just guides to help teachers develop their own localized models. This implies that reflection and keeping of learning journals should be encouraged among teachers to enable them to be innovative and creative. It is clear from the above quotations that if these teachers were truly reflecting on their practice and learning from their experiences, they would have had a lot to write in their journals. From most of their statements there were ways they could have recognized and maximized their personal values, beliefs and learning for future actions.

\section{Conclusion and Recommendations}

One finding in this study is that primary school teachers consider the TESSA OER as user-friendly, influencing their classroom practices and methods. Also, the resource could help them in their work greatly. They have indicated that this package could help them produce better learning environments. However, they did not employ the elements of Kolb and Gibbs experiential/reflective learning cycles, which were supposed to have been the frameworks to understand their learning from their reflections. There were several instances that if these frameworks were used to understand their feelings and analysis of their situations useful conclusions leading to future action planning could have been revealed as well as more deep learning. This was evident in the teachers' submissions of looking forward to planning interesting and exciting environments for their learners by using games, songs, videos and audios, which are strategies that children enjoy.

It is being recommended that reflective teaching, learning and writing should be introduced as part of teachers' in-service training sessions during their professional capacity building programmes. Again, since most schools are supposed to be organizing teacher-support team activities, which are school-based, the concept of reflective learning and skills needed to 
practice it should be recommended to District Directors of Education and their facilitators. In line with this, the University should assist the directorates with resources, including experts in the subject, practice-based assignments and projects in reflective learning for teachers. Further, the regular pre-service teachers who are supposed to be guided to write their reflective practice assignments during their internship should be supervised well for them to acquire all the necessary skills.

Overall, the study has highlighted the need for teacher education programmes to focus on emphasizing teachers' reflective learning and writing culture as well as keeping reflective journals for continuous professional growth. This technique could help them to develop skills that cater for improvement in their classrooms and meeting the needs of their learners. Again, the study has thrown light on the need for teachers to collaborate and network among themselves as they come across new approaches in teaching and learning to improve their practice. It has revealed the need for teacher education institutions to support both in-service and pre-service teachers in their practice with new pedagogies for better students learning.

\section{References}

Bhowmik, M., Banerjee (Roy), B., \& Banerjee, J. (2013). Role of Pedagogy in Effective Teaching, Basic Research Journal of Education Research and Review, 2(1) 01-05.

Boud, D., Cohen, R., \& Walker, D., (1993). Using Experience for Learning. London: Open University Press.

Boyd, E. M., \& Fales, A. W., (1983). Reflective Learning: Key to Learning from Experience, Journal of Humanistic Psychology, 23(2) 99-117.

Chan, C. (2009). Assessment: Reflective Journal, Assessment Resources@HKU, University of Hong Kong Retrieved April 25, 2015 from URL:http://ar.cetl.hku.hk

Clarke, M. (2004). Reflection: Journals and reflective Questions: A strategy for Professional Learning, Australia Journal of Teacher Education, 29(2) 1-13.

Dewey, J. (1933). How we Think: A restatement of the relation of Reflective thinking to the educative process. Boston, D.C: Heath.

Dietz, M. E. (1998). Responses as Frameworks for Change. Victoria, Australia: Hawker Brownlow Education.

Gibbs, G. (1998). Learning by doing: A guide to teaching and learning. London: FEU.

Kolb, D. A. (1984). Experiential learning: experience as the source of learning and development. Englewood Cliffs, New Jersey: Prentice Hall.

Marshall, C., \& Rossman, G. B. (1999). Designing Qualitative Research [3rd ed.]. Thousand Oaks: Sage.

Marshall, C., \& Rossman, G. B. (2006). Designing Qualitative Research (5th ed.). Thousand Oaks: Sage. 
Mezirow, J. (1991). Transformative Dimensions of Adult Learning. San Francisco: Jossey-Bass.

Monash University. (2007). Learning Support-The Reflective learning process. Retrieved January 28, 2015 from http:/www.monash.edu.au/lls/llonline/writing/medicine/reflective/ 3.xml

Moon, J. (1999). Reflective Writing: some initial guidance for students. Retrieved August 20, 2012 from http://www.services.ex.ac.uk/cas/employability/students/reflective.htm

Park, J. Y., \& Son, J. B. (2011). Expression and Connection: The Integration of the Reflective Learning Process and the Public Writing Process into Social Network Sites. MERLOT Journal of Online Learning and Teaching, 7(1) 170-178.

Pratt, D. D. (1992). Conceptions of Teaching, Adult Education Quarterly, 42(4) 203-220

UNESCO. (2005). Education for All: The Quality Imperative. UNESCO: Paris.

Wolfenden, F. (2008). The TESSA OER Experience: Building sustainable models of production and user implementation. Journal of Interactive Media in Education. Retrieved March 14, 2015 from http://jime.open.ac.uk/articles/10.5334/2008-3/

\section{Copyright Disclaimer}

Copyright reserved by the author(s).

This article is an open-access article distributed under the terms and conditions of the Creative Commons Attribution license (http://creativecommons.org/licenses/by/3.0/). 